\title{
TEMPOS DE PANDEMIA
}

\author{
Pandemic times
}

Tempos de pandemia

MARTINA SPOHR ${ }^{{ }^{*}}$

DOI: https://doi.org/10.1590/S2178-149420210201

'Escola de Ciências Sociais, Centro de Pesquisa e Documentação de História Contemporânea do Brasil, Fundação Getulio Vargas - Rio de Janeiro (RJ), Brasil.

*Doutora em História Social, Universidade Federal do Rio de Janeiro (martina.spohr@fgv.br).

(D) https://orcid.org/0000-0003-1461-5367 
ste número da Revista Estudos Históricos é marcado especialmente pela contemporaneidade e interdisciplinaridade de seus artigos. A ideia do dossiê Tempos de pandemia surge pela urgência de debates e análises científicas promovidos em diferentes áreas com o advento da pandemia de COVID-19, decretada mundialmente no dia 11 de março de 2020. Como resultado, temos uma edição robusta, composta de trabalhos com pontos de vista metodológico e temático diversos.

Como linha comum dos artigos, observamos o debate sobre o tempo em diferentes perspectivas. A própria edição deste número pressupõe uma reflexão sobre tempo, na medida em que reunimos nesse conjunto incursões acadêmicas desenvolvidas no auge da pandemia, no seio de seus acontecimentos. Encontramo-nos, ainda, sem respostas concretas e objetivas sobre o curso desse longo processo. Reflexões sobre o tempo histórico e sobre a produção de pesquisas científicas pela ótica dinâmica do momento histórico são fruto de debates e discussões de longa data.

0 tempo social, como proposto por Fernand Braudel (1949), pode ser dividido metodologicamente em três momentos: média, curta e longa duração. 0 exercício de pesquisa deve, sempre, levar em consideração a construção e o recorte temáticos nessas três perspectivas, que caracterizam o tempo múltiplo, compondo as principais características do tempo social.

Em suma, temos a longa duração como o âmbito das estruturas, a média duração como o tempo das conjunturas e a curta duração como a medida da atualidade, da vida do dia a dia. Os artigos que compõem este dossiê sobre a pandemia, acontecimento histórico contemporâneo, assim como as pesquisas e as autorias, pode dar uma primeira impressão equivocada. 0 distanciamento analítico na área das ciências humanas, há tempos colocado como essencial para o desenvolvimento de pesquisas científicas, caiu por tese há algumas décadas, especialmente com a eclosão do campo da história do tempo presente.

Nesse bojo, temos a proposição do tempo histórico de Reinhart Koselleck (2014), o tempo estratificado, formado por diferentes camadas de tempo, independentes e interdependentes entre si, proporcionando a base reflexiva de continuidades e rupturas de processos históricos. A proposta de Koselleck subsidia as análises do tempo presente com base no entendimento desses processos como constructos sociais inter-relacionados, proporcionando a base analítica da compreensão de eventos contemporâneos por seus cientistas sociais.

0 coletivo de reflexões analisa em sua complexidade questões estruturais como as desigualdades sociais da sociedade contemporânea, refletindo diretamente no acesso à educação e à saúde no Brasil e no mundo. Nesse conjunto, encontramos reflexões de longa duração com perspectivas históricas, demonstrando os impactos políticos e sociais da gripe espanhola de 1918 na sociedade, 0 
processo de exclusão digital de setores sociais e seus impactos na educação à distância e a questão da aprendizagem, bem como os muros epidemiológicos construídos ao longo de décadas.

Encontramos também análises estruturais sobre as democracias latino-americanas e sobre os Estados Unidos, o impacto econômico em populações historicamente em situação de vulnerabilidade, apontando as continuidades de um processo histórico estrondosamente desigual. Ainda pensando na perspectiva da longa duração, vemos a construção da memória social ao longo dos anos e os desafios enfrentados pela gestão e recuperação de documentos produzidos em meio digital. Análises sobre a estrutura midiática brasileira e as fronteiras entre o público e o privado, a construção social de contextos afrorreligiosos e suas nuances políticas, a utilização midiática para defesa de pautas específicas e práticas culturais de uma sociedade em isolamento compõem o tempo histórico de longa duração presente neste dossiê.

No contexto de média duração, no tempo das conjunturas, podemos inferir importantes recortes com elementos de continuidades e rupturas subsidiando o estudo do tempo presente. Envolvendo elementos como os citados no contexto de longa duração, observamos o recorte analítico de média duração no que diz respeito à compreensão conjuntural dos temas em questão. Como linha comum aos artigos, observamos a reconstrução de contextos históricos anteriores à pandemia de COVID-19, buscando alinhar as expectativas de análise políticas, econômicas e culturais na camada mais ampla do tempo histórico a fim de reconhecer os aspectos atingidos pelo momento atual. A preocupação com o contexto histórico conjuntural é inerente e presente em todas as análises, independentemente do tema trabalhado. Ainda que pareçam temáticas bastante diferentes, os textos aqui reunidos nos permitem traçar um quadro conjuntural de extrema qualidade para compreender o advento histórico da pandemia, nosso elemento de curta duração.

Nesse ponto, vemos detalhadamente o recorte mais específico dos artigos. Em grande parte, 0 ano de 2020 atua como medida da atualidade. Seja no debate acerca de questões educacionais como nos artigos "Direito ou privilégio? Desigualdades digitais, pandemia e os desafios de uma escola pública", de Renata Mourão Macedo, e "Aprendizagem histórica em tempos de pandemia", de Cristiano Nicolini e Kenia Erica Gusmao Medeiros, cujos recortes dão conta da urgente mudança para o ensino a distância e suas consequências, seja no debate sobre questões culturais e de memória nos textos de Alejandra Josiowicz, "Humanidades digitais e literatura nas redes sociais: 'um placebo sanador em tempos de COVID-19'", o artigo de Isabella Vivente Perrotta e Lucia Santa Cruz, "Objetos da quarentena: urgência de memória", e o texto de Vítor Queiroz, "Quando o ser-humano cria, Iku vem à Terra: as mediações de Exu, a onipresença da morte e a COVID-19 em dois contextos afrorreligiosos".

Tratando especificamente de questões políticas e econômicas que envolvem a gestão da pandemia em países da América Latina, temos o artigo de Rafael Araujo e Érica Sarmiento, 
"A América Latina, a COVID-19 e as migrações forçadas: perspectivas em movimentos, muros epidemiológicos e sombrias imagens", apontando as medidas atuais do tempo histórico e os reflexos na migração forçada de populações vulneráveis, e a contribuição especial de André Pagliarini, "Possible Futures: COVID-19 as Historical Turning Point", recortando a análise específica sobre a importância desse debate para a historiografia presente.

Analisando especialmente 0 aspecto midiático da pandemia, temos os artigos de Flavia Pinto Leiroz e lgor Sacramento, "Cronotopias da intimidade catastrófica: testemunhos sobre a COVID-19 no Jornal Nacional", mostrando o recorte do maior jornal diário do Brasil e seus impactos sobre a relação entre público e privado em nossa sociedade, e o texto de Luciana Almeida, "Pandemia, 'agro' e 'sofrência': jornalismo, propaganda e entretenimento no debate público sobre 0 modelo agrícola", mostrando a relação instantânea da pandemia na indústria cultural nacional.

Em entrevista concedida por James Green, realizada por mim e por Ronald Canabarro, em que aplicamos a temporalidade múltipla no decorrer das perguntas, buscou-se criar uma narrativa que abarcasse suas opiniões estruturais das sociedades brasileiras e norte-americanas, chegando às análises conjunturais mais recentes de ambos países de maneira que confluísse no momento atual da pandemia, suas consequências políticas, econômicas e culturais da COVID-19 no mundo pela ótica do historiador e militante norte-americano.

Quando falamos em tempos de pandemia, estamos definindo tempo como social, como o tempo composto de diacronias e sincronias, continuidades e rupturas. A urgência evidenciada pelas necessidades informacionais e analíticas, que perpassam diferentes temas, nesse último ano pandêmico pelo qual nossa sociedade passou em todo o globo estão reunidas nesse dossiê interdisciplinar e diverso que montamos. Nosso desejo é o de que possamos reler suas páginas como documentos históricos em alguns anos, proporcionando compreensões fundamentadas e científicas da história presente.

Por fim, e em nome da Escola de Ciências Sociais da Fundação Getulio Vargas (FGV CPDOC), prestamos nossa solidariedade coletiva às famílias de 3 milhões de pessoas ${ }^{1}$ em todo mundo vítimas da COVID-19.

\section{NOTA}

1 Dados coletados em: https://www.worldometers.info/coronavirus/. Acesso em: 12 abr. 2021.

\section{REFERÊNCIAS BIBLIOGRÁFICAS}

BRAUDEL, F. La Méditerranée et le monde méditerranéen à l'époque de Philippe II. Paris: Armand Colin, 1949. KOSELLECK, R. Estratos de Tempo: estudos sobre a História. Rio de Janeiro: Contraponto/Ed. PUC-RJ, 2014. 